\title{
Properties of Gypsum-PCM Based Mortars for Interior Plastering of Construction Systems
}

\author{
Nelson Silva ${ }^{1, a}$, José B. Aguiar ${ }^{1, b}$, Luís M. Bragança ${ }^{1, c}$, Teresa Freire ${ }^{2, d}$, \\ Isabel Cardoso $3, \mathrm{e}$ \\ ${ }^{1}$ University of Minho, Department of Civil Engineering, Campús de Azurém, 4800-058 Guimarães, \\ Portugal \\ ${ }^{2}$ Sival, Industrial Society of Várzea, Rua da Sival, Várzeas, 2425-879 Souto da Carpalhosa, Leiria, \\ Portugal \\ ${ }^{3}$ Micropolis, Production and Development of Powder Polymers, Lt. 14, Ruães, 4700-565 Mire de \\ Tibães, Braga, Portugal \\ anelson.silva@civil.uminho.pt, baguiar@civil.uminho.pt, cbraganca@civil.uminho.pt,

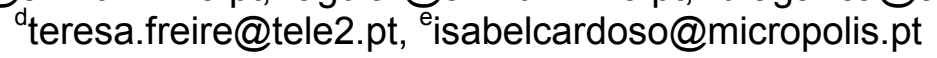

Keywords: Gypsum Plasters, PCM, Interior Plastering, Energy Consumption Reduction.

\begin{abstract}
Incorporating phase change materials (PCM) in plasters is an effective solution both for more efficient use of energy and its consumption reduction, because it allows the use of free energy in the environment, by latent heat storage. As PCM has not binder properties, it is expected to decrease mechanical properties of the final mortar. Also the density of the mortar decreases due to PCM lighter specific weight. In order to be used as a final coat for wall plastering, it must verify the requirements of the respective European Standard. This paper presents the results of the composition development and mechanical properties (flexural, compressive and adhesive strengths) testing and validation of three different gypsum mortars, in order to select the appropriate one for thermal testing in test cells. The results show that the effective decrease in the studied characteristics of the mortar does not inhibit the use for plastering, as requirements are achieved by the three studied compositions.
\end{abstract}

\section{Introduction}

Phase change materials (PCM) have been incorporated in construction elements for more than 30 years now. Major applications of PCM in buildings include passive storage systems such as trombe walls, wallboards, building blocks and plasters and active storage systems such as floor heating and ceiling boards [1].

Micro-encapsulation makes it possible to integrate PCM into conventional building materials with the advantages of easy application, good heat transfer and no need for protection against destruction.

The use of PCM in gypsum plasters has been investigated by Schossig et al. [2] using a PCM with a melting range temperature of $24-26^{\circ} \mathrm{C}$. A plaster with $40 \%$ weight PCM and $6 \mathrm{~mm}$ thickness and another with $20 \%$ weight PCM and $15 \mathrm{~mm}$ thickness were studied. Results showed, in both cases a decrease in the higher temperature of around $4{ }^{\circ} \mathrm{C}$ with a delay in the maximum temperature of 1 hour.

In Portugal, most residential buildings use gypsum multilayer plastering systems. The incorporation of PCM in a very thin finishing plaster layer is therefore interesting, allowing a smaller quantity of PCM to be incorporated, while promoting higher heat transfer rates by its proximity with the room environment. 
In order to access the economical viability of this material and technique, by quantifying active cooling and heating energy savings, a complete research work was planned as follows:

i) Selection and development of the gypsum mortars and PCM;

ii) Mechanical testing in specimens, of the gypsum and gypsum-PCM based mortars;

iii) Thermal and mechanical testing in pilot scale walls, of the gypsum-PCM based mortar;

iv) Thermal behaviour testing, in test cells, of the gypsum-PCM based mortar, and comparison with gypsum mortar. Thermal behaviour of gypsum-PCM based mortar in-situ.

The results presented in this paper refer to mechanical testing phases i) to iii) of the above mentioned plan.

\section{Experimental Programme}

Materials. In this experimental work, five different gypsum plasters were used. Two, referred as PP for projection plaster and MA for manual application plaster, are commercially available. Both contain over $50 \%$ of gypsum binder. PP contains lime, and both contain fillers of different fineness, water retentors and setting retarders.

The other three, formulations F3, F4 and F5, were specially developed for this research, based on MA and including in their composition different percentages of fillers and $\mathrm{CaSO}_{4} \cdot 1 / 2 \mathrm{H}_{2} \mathrm{O}$.

The microencapsulated PCM used consists in a dispersion of hexadecane paraffin wax, encapsulated in a melamine-formaldehyde resin, with an average particle size distribution of 20-30 $\mu \mathrm{m}$, melting temperature around $20^{\circ} \mathrm{C}$ and a latent heat of fusion of $140 \mathrm{~kJ} / \mathrm{kg}$.

Test procedures. All tests were carried out according to European Standard EN 13279-2:2004.

For each mixture, water/plaster (W/P) ratio, flexural and compressive strengths were determined. At least three prismatic test specimens were cast at sizes of $40 \times 40 \times 160 \mathrm{~mm}^{3}$, demolded after 24 hours and then stored for 7 days at $23 \pm 2{ }^{\circ} \mathrm{C}$ and $50 \pm 5 \%$ relative humidity. The specimens were then dried to constant mass at $40 \pm 2{ }^{\circ} \mathrm{C}$ and cooled to room temperature. Adhesive strength testing was carried in test walls, as described ahead.

According to conventional construction techniques, three ceramic brick walls of $1.60 \times 0.90 \mathrm{~m}^{2}$ were built and plastered with projection mortar PP. Finishing layers of plasters F3, F4 and F5 where then manually applied. Both PP and finishing plasters $40 \times 40 \times 160 \mathrm{~mm}^{3}$ prisms were cast in order to compare the results with laboratory test specimens. Bond strength between layers was measured after 28 days, both in non-painted and painted finishing plaster surfaces, in five different local sites.

For bond strength, circular test areas could not be cut with the core cutter due to the high tangential force induced in the plaster, enough to destroy the layers. Therefore the procedure used was to glue, with two component epoxy resin, the pull-heads directly to the surface. The adhesive strength was then calculated, dividing the failure load by the test area.

During this period, optical inspection on the surface of the applied plasters was done, in order to evaluate support compatibility between plaster layers.

\section{Results and Discussion}

In order to study the influence of PCM incorporation in the mechanical properties of the gypsum plaster, different percentages of PCM were tested with MA. Results are shown in Fig. 1. The incorporation was made by weight replacement. 


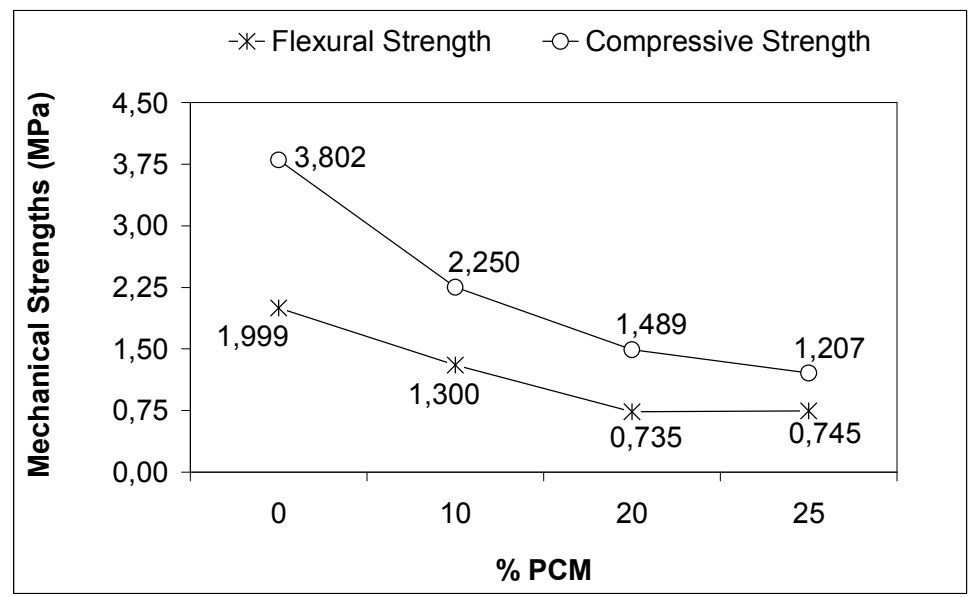

Fig. 1 - Variation of mechanical properties of MA with PCM incorporation.

The incorporation of only $10 \%$ PCM in the gypsum mixture reduces around $35 \%$ flexural strength and $40 \%$ compressive strength of the final plaster. However, from $10 \%$ to $25 \% \mathrm{PCM}$ incorporation, strength reduction is smaller than 30\%, suggesting an accommodation of the burst capsules and paraffin wax, in the middle of gypsum crystals. More, from $20 \%$ to $25 \%$ PCM incorporation, a small increase in flexural strength and a decrease of only $8 \%$ in compressive strength were observed. The overall decrease was $63 \%$ for flexural strength and $68 \%$ for compressive strength.

It was observed that the incorporation of PCM decreases the workability. An increase of up to $10 \%$ in the $\mathrm{W} / \mathrm{P}$ ratio was necessary, in order to achieve comparable flow table pats. This may be explained by the suspension formed between the PCM and water, therefore decreasing the dispersion of the plaster in water and its hydration available sites, due to PCM smaller particle size.

The ideal W/P ratio leading to the EN 13279-2 workability standard $(165 \pm 5 \mathrm{~mm})$ was around $70 \%$ for MA and for MA incorporating $25 \%$ PCM, around $80 \%$ was determined, without however achieving the desired compressive strength of at least $2 \mathrm{MPa}$.

From preliminary results, $25 \%$ weight was defined as the amount of PCM to incorporate through the rest of the research work.

Modified compositions of MA were developed in order to fulfil the standard requirements. F3 contains limestone aggregates, F4 contains more gypsum binder than MA and F5 refers to a composition in which both described modifications were incorporated.

For these mortars, 25\% PCM incorporation was set and compared with the standard compositions. Fig. 2 and 3 present the results obtained for these mortars.

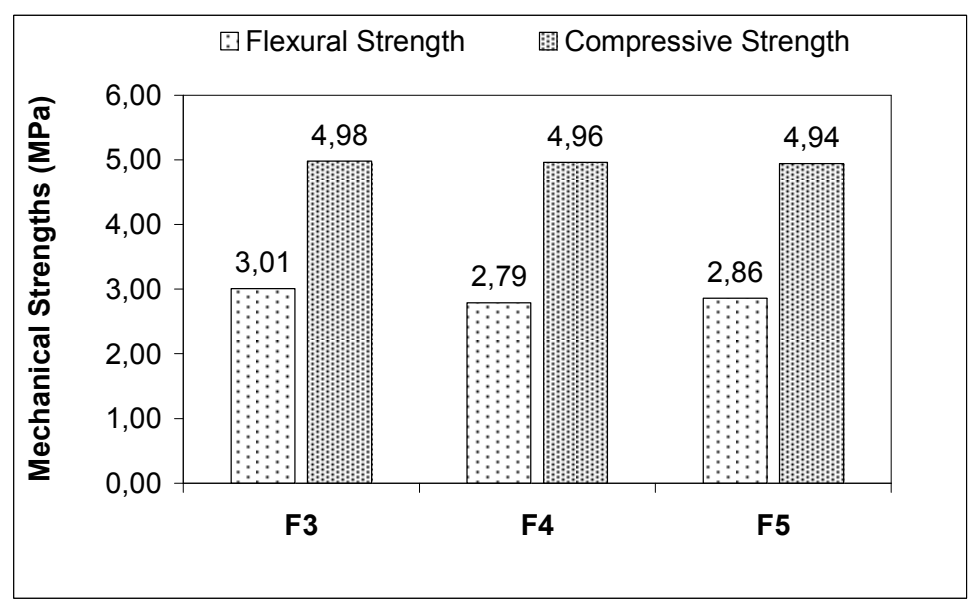

Fig. 2 - Mechanical properties of modified compositions ( $0 \%$ PCM). 


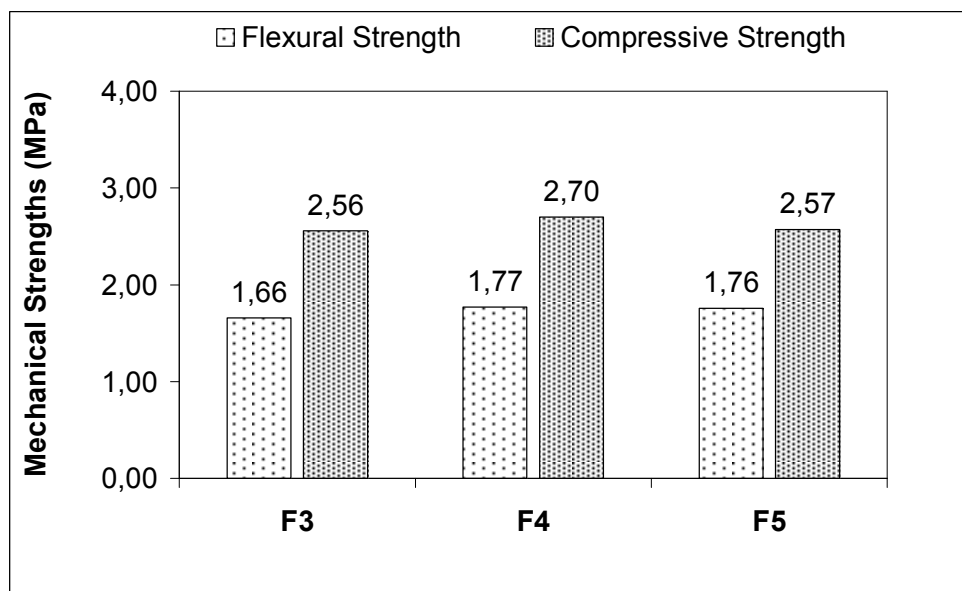

Fig. 3 - Mechanical properties of modified compositions incorporating 25\% PCM.

As seen before for MA, the incorporation of 25\% PCM decreases the strengths of the mortars. For the modified compositions decreases of $37 \%$ to $45 \%$ in flexural strength and $45 \%$ to $48 \%$ in compressive strength were observed. Compositions with higher binder content (F4 and F5) presented the smallest reductions in both properties.

When compared to MA all modified compositions presented significantly better performances. Without PCM, increases up to $50 \%$ in flexural strength and around $30 \%$ in compressive strength were registered. Incorporating PCM, increases up to $40 \%$ in flexural strength and $58 \%$ in compressive strength were achieved.

No significant differences between formulations were established, however F4 presented the best overall performance, both in standards and incorporating PCM.

Ideal W/P ratio of $70 \%$ for the standards and $80 \%$ with PCM were defined for these compositions by comparison with MA.

To validate the results and the suitability of the mortars tested in laboratory the application of the plasters was done according to conventional construction techniques in test walls. Projection plaster PP was applied underneath the manual finishing modified plaster layer (F3, F4 and F5 containing $25 \%$ PCM). Fig. 4 presents the results of in-situ mechanical testing carried.
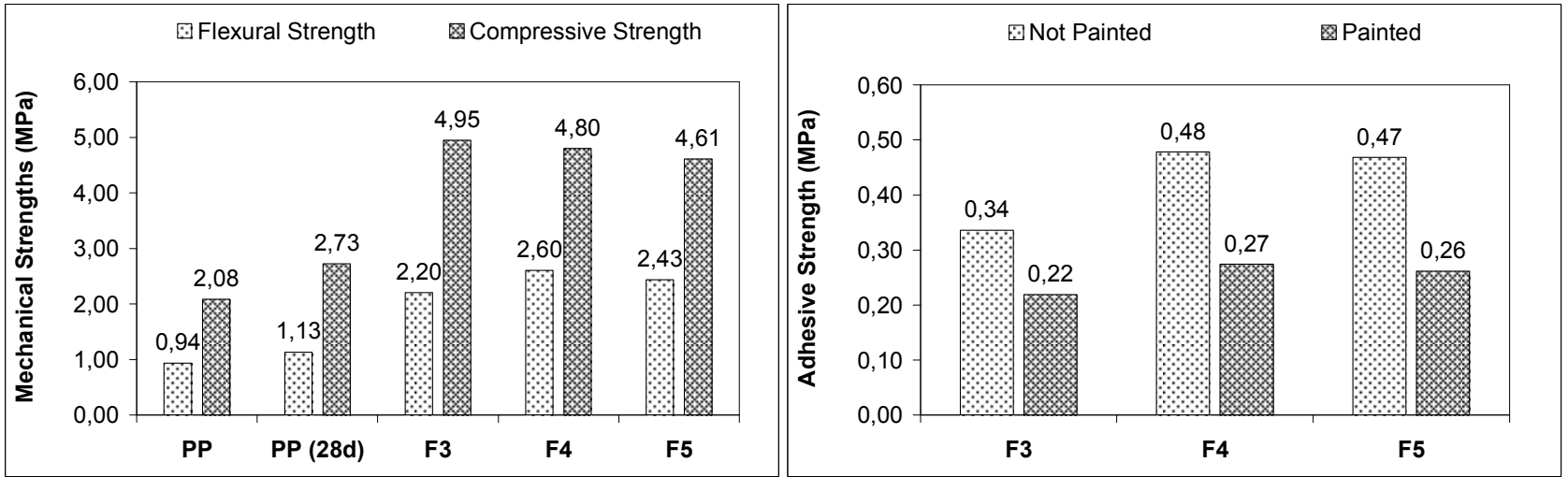

Fig. 4 - Strengths of test wall mortars: (a) Flexural / Compressive and (b) Adhesion.

In this case higher strengths were achieved due to the lower W/P ratio used. Projection plaster itself achieves flexural and compressive strengths that satisfy the requirements of EN 13279, therefore, although the final plastering system is composed by a thin layer of PCM plaster, the complete system achieves the requirements of the standard. 
Adhesion between layers also showed very good results, much above the requirements of the standard $(0.1 \mathrm{MPa})$, both in non-painted and in painted plaster surfaces. It was observed that, although similar flexural and compressive strengths were achieved by the three compositions, higher binder content improved significantly adhesion strength, especially in non-painted surfaces, for more active hydration sites are available. Table 1 presents the fracture patterns for the adhesive tests carried.

Table 1 - Fracture patterns for bond strength tests.

\begin{tabular}{|c|c|c|}
\hline \multirow{2}{*}{ Plaster } & \multicolumn{2}{|c|}{ Fracture Pattern } \\
\cline { 2 - 3 } & Non-Painted FL Surface & Painted FL Surface \\
\hline \multirow{4}{*}{ F3 } & Cohesion (C) - (100\% PP) & Adhesion (A) - (80\% Interface P-FL) \\
& Cohesion (C) - (75\% PP) & Cohesion (C) - (90\% Interface FL-PP) \\
& Adhesion (A) - (Interface FL-PP) & Cohesion (C) - (80\% Interface FL-PP) \\
& Cohesion (C) - (50\% PP) & Adhesion (A) - (90\% Interface P-FL) \\
& Adhesion (A) - (Interface FL-PP) & Adhesion (A) - (90\% Interface P-FL) \\
\hline \multirow{4}{*}{ F4 } & Adhesion (A) - (Interface FL-PP) & Cohesion (C) - (100\% Interface FL-PP) \\
& Adhesion (A) - (Interface FL-PP) & Cohesion (C) - (90\% Interface FL-PP) \\
& Adhesion (A) - (Interface FL-PP) & Adhesion (A) - (60\% Interface P-FL) \\
& Cohesion (C) - (75\% PP) & Cohesion (C) - (100\% Interface FL-PP) \\
& Cohesion (C) - (50\% PP) & Cohesion (C) - (100\% Interface FL-PP) \\
\hline \multirow{4}{*}{ F5 } & Cohesion (C) - (50\% PP) & Cohesion (C) - (100\% Interface FL-PP) \\
& Adhesion (A) - (Interface FL-PP) & Cohesion (C) - (100\% Interface FL-PP) \\
& Adhesion (A) - (Interface FL-PP) & Cohesion (C) - (100\% Interface FL-PP) \\
& Adhesion (A) - (Interface FL-PP) & Cohesion (C) - (100\% Interface FL-PP) \\
& Cohesion (C) - (25\% PP) & Cohesion (C) - (100\% Interface FL-PP) \\
\hline
\end{tabular}

$(\mathrm{PP}=$ Projection Plaster; FL = Finishing Layer; $\mathrm{P}=$ Paint $)$

In non-painted plaster surfaces, adhesion or cohesion fracture occurred, either in the plaster finishing layer itself or in the background plaster PP, showing that in either case, adhesive strength is even greater than the test value.

In painted surfaces, two different scenarios were observed: for the finishing layer with lower binder content (F3), adhesive fracture between P and FL occur showing, in general, lower adhesion of the paint to the final plaster, while, for higher binder content, almost only cohesive fracture occurred.

\section{Conclusion}

Through the experimental research work carried several conclusions could be drawn:

- PCM incorporation decreases significantly the mechanical properties of the gypsum mortars;

- Three different compositions were established, in order to fulfil the requirements of the EN standard. For the workability range defined, a $75-80 \% \mathrm{~W} / \mathrm{P}$ ratio was determined, with no significant difference between formulations;

- Comparison between formulations showed that F4 is the most suitable one to proceed the experimental research due to higher flexural, compressive and adhesive strengths, both in nonpainted and in painted surfaces. More, the production cost of F4 is around 5\% lower than the other two.

\section{Acknowledgments}

The research work presented in this paper is part of the ADI/2006/V4.1/0035, "GESREV Development of new integrated system, based in gypsum, for interior plastering of construction systems" research project, financed by IDEIA - POCI 2010 Program.

\section{References}

[1] J. Monteiro, The Use of Active Materials for Thermal Performance Improvement of Constructive Systems, Thesis of Master of Science in Civil Engineering, University of Minho, Guimarães, Portugal, 2005 (in Portuguese).

[2] P. Schossig, H.-M. Henning, S. Gschwander and T. Haussmann: Solar Energy Materials and Solar Cells Vol. 89 (2005), p.297. 